2015

\title{
Kinematic Barrier Constraints on the Magnitudes of Additional Great Earthquakes Off the East Coast of Japan
}

John P. Loveless

Smith College, jloveles@smith.edu

Brendan J. Meade

Harvard University

Follow this and additional works at: https://scholarworks.smith.edu/geo_facpubs

Part of the Geology Commons

\section{Recommended Citation}

Loveless, John P. and Meade, Brendan J., "Kinematic Barrier Constraints on the Magnitudes of Additional Great Earthquakes Off the East Coast of Japan" (2015). Geosciences: Faculty Publications, Smith College, Northampton, MA.

https://scholarworks.smith.edu/geo_facpubs/6 


\section{Kinematic Barrier Constraints on the Magnitudes of Additional Great Earthquakes Off the East Coast of Japan}

\section{by John P. Loveless and Brendan J. Meade}

Online Material: Figures showing potential areas and magnitudes of earthquakes rupturing partially coupled regions of the subduction zones.

\section{INTRODUCTION}

In the wake of the 2011 great Tohoku-Oki, Japan, earthquake, questions were asked about the extent to which this earthquake ruptured a part of the subduction zone that had been strongly coupled in the decades prior to the event (Avouac, 2011; Lay and Kanamori, 2011; Loveless and Meade, 2011). The primary means for investigating this question is the analysis of interseismic geodetic data. These data record both tectonic motions and the accumulation of elastic strain the upper crust. Combined with elastic dislocation and block models, Global Navigation Satellite System (GNSS) data from the GNSS Earth Observation Network System (GEONET) array had been used to estimate the spatial variation in interseismic coupling (defined as the fraction of relative motion between tectonic plates that contributes to elastic strain accumulation) along the Japan trench subduction interface prior to the occurrence of the 2011 event (Nishimura et al., 2004; Suwa et al., 2006; Hashimoto et al., 2009; Loveless and Meade, 2010). Each of these estimated interseismic coupling distributions identified a partially to strongly coupled region, extending for $\sim 400 \mathrm{~km}$ between $36^{\circ}$ and $40^{\circ}$ north latitude along the Japan trench, approximately bounding the lateral and down-dip extents of the coseismic rupture (Loveless and Meade, 2011). However, none of these estimates show a perfect spatial correspondence between the coseismic rupture extent and complete preseismic coupling. Rather, the coseismic rupture was laterally bounded by regions of the Japan subduction zone with a coupling fraction $c$ of $\sim 0.3$, in which $30 \%$ of the relative plate motion contributes to elastic strain accumulation during the interseismic regime (Loveless and Meade, 2011). This spatial relationship could result from insufficient elastic strain accumulation around portions of the interface characterized by lower, but nonzero, coupling values, which act as kinematic barriers to rupture propagation.

In this article, we develop candidate rupture scenarios across the Japan, Sagami, and Nankai subduction zones, based on spatial variations in interseismic coupling and empirical earthquake parameter scaling laws. Specifically, we examine spatial clusters of the subduction interfaces within which the coupling exceeds a given fraction of plate convergence rate and estimate the moment magnitude of an earthquake that could occur within that region, based on a scaling relationship between cluster area and earthquake magnitude. We consider cases in which the shallowest portions of the plate interfaces, near the subduction trenches, are assumed to creep interseismically and in which they are allowed to be coupled. The assumed kinematic behavior affects potential rupture areas by up to $40 \%$, though this difference may be reduced if coseismic dynamic overshoot (which permits ruptures to propagate into interseismically creeping regions) is prevalent near the trenches.

\section{POTENTIAL RUPTURE EXTENTS FROM SPATIAL VARIATIONS IN INTERSEISMIC COUPLING}

We consider two different interseismic coupling distributions for the Japan, Sagami, and Nankai subduction zones. Both are based on block models of the greater Japan region (Loveless and Meade, 2010), which consider the role of long-term microplate rotations and elastic earthquake cycle processes on the network of faults cutting the Japanese islands and the subduction zones offshore, constrained by GPS observations spanning the interval from 1997 to 2001. This observational window represents the longest span of time since the establishment of the GEONET array during which there were no large $M_{\mathrm{w}}>7.0$ earthquakes (Fig. 1) that would have significantly affected interseismic velocities. For both coupling cases, the geometry of each subduction zone interface is consistent with geophysical data constraints (Furuse and Kono, 2003; Hirose et al., 2008; Toda et al., 2008) and parameterized using gap free meshes of 
2621 (Japan), 231 (Sagami), and 1902 (Nankai) triangular dislocation elements (TDEs) embedded in a homogeneous elastic half-space (Comninou, 1973; Jeyakumaran et al., 1992; Thomas, 1993; Meade, 2007).

The first interseismic coupling model is similar to that presented in Loveless and Meade (2010) and is constrained by the assumption that the shallowest part of the subduction zone interface creeps at a rate equal to the plate rate $v_{p}$. This kin- ematic model approximates the physical concept that the shallowest portions of the megathrust are bounded by stably sliding clays incapable of accumulating interseismic elastic strain (e.g., Oleskevich et al., 1999). The second interseismic coupling model is similar but relaxes the constraint that the subduction zones must creep at the trench, which results in estimated coupling very near the trench, similar to that interpreted from seafloor geodetic observations offshore of Peru (Gagnon et al.,

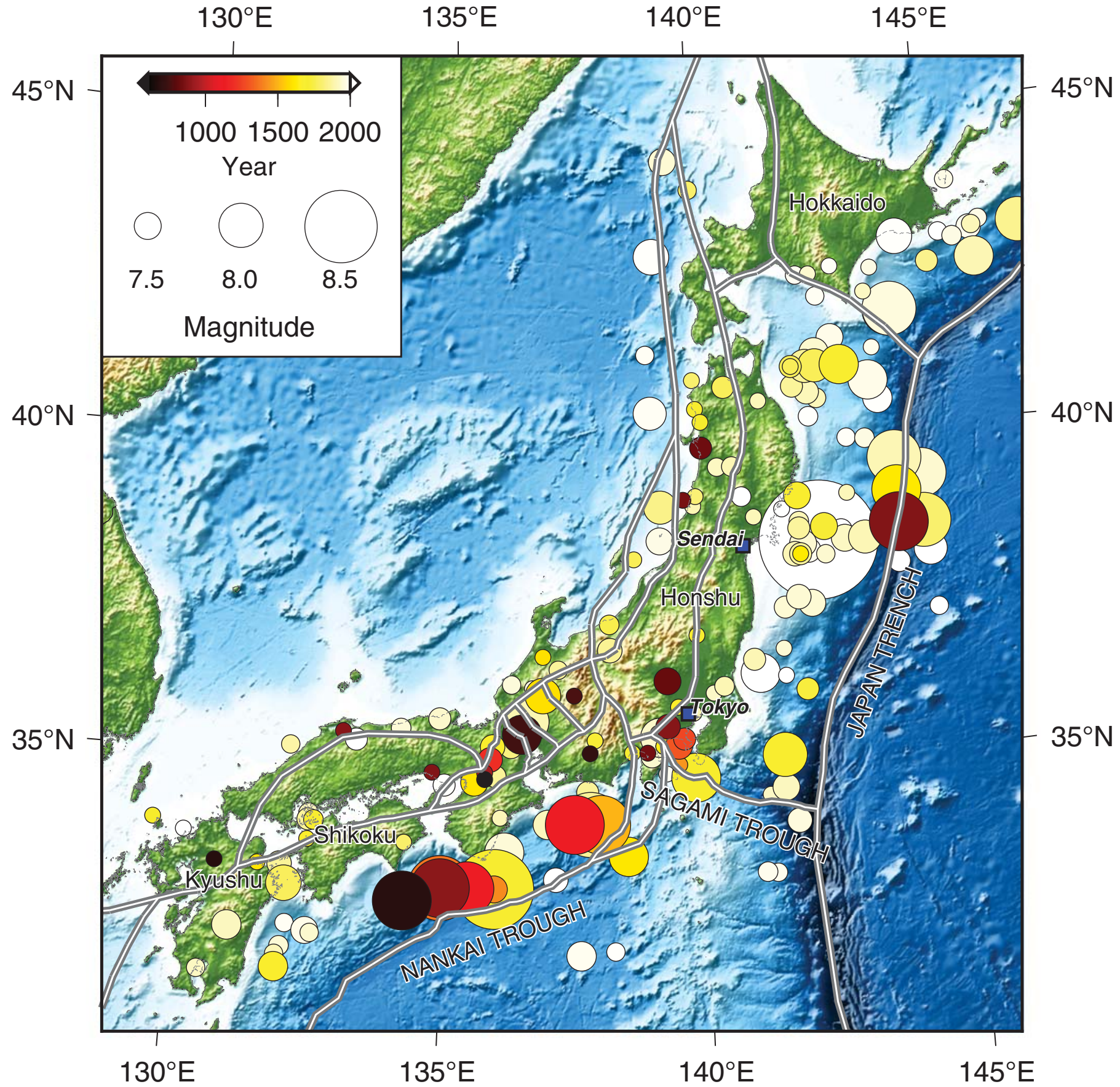

A Figure 1. Map of seismicity with estimated or measured magnitude $M_{\mathrm{w}} \geq 7.0$ since the year 599, with circle radius proportional to magnitude and color indicating date of occurrence. Earthquakes through 2010 are based on Utsu (2004), and those since 2010 are from the U.S. Geological Survey (USGS). Gray and white lines show interseismic elastic block model boundaries from Loveless and Meade (2010). 
2005). Both interseismic coupling distributions are smoothed using a weighted Laplacian smoothing matrix. The weight for a given TDE is inversely proportional to the sum of the partial derivatives relating unit slip to displacement at GPS stations. This leads to greater smoothing near the trench where the great distance from GPS stations leads to poor sensitivity of estimated slip to observed velocities (Loveless and Meade, 2010; Evans and Meade, 2012). The lack of resolution of near-trench behavior by land-based geodesy is a primary motivation behind our presentation of models both with and without the trench creep constraint.

Features consistent in both interseismic coupling distributions, based on pre-Tohoku-Oki observations, include two strongly coupled patches on each of the Japan and Nankai subduction zones, as well as 100\% coupling along the southwestern portion of the Sagami subduction zone (Fig. 2). The region of coupling offshore of northern Honshu has been interpreted to correlate positively with the coseismic rupture extent of the 2011 Tohoku-Oki earthquake (Avouac, 2011; Loveless and Meade, 2011).
To quantitatively assess the relationship between estimated interseismic coupling coefficients and potential ruptures, we calculate the area of regions contained within a constant coupling fraction value $c$ and map these to potential earthquake moment magnitudes using empirical scaling relationships (Wells and Coppersmith, 1994) that relate rupture area to magnitude for reverse-slip faults. We emphasize that by using this area scaling relationship, we infer the potential coseismic rupture extent, and not the details of the slip distribution, from interseismic coupling extent. At a coupling fraction $c=0$, the area that could be considered to rupture each subduction zone is the total area of that subduction zone, though this case might be considered an overestimate as there would be no accumulated strain to be released in regions where $c=0$. At the other extreme, $c=1$, only the completely coupled regions would be considered to slip coseismically. Here, we neglect coupling fractions $c<0$ corresponding to regions where we estimate reverse-sense slip during the interseismic period, which we interpret to reflect aseismic creep on the plate interface at a rate faster than plate convergence (e.g., beneath eastern Iwate

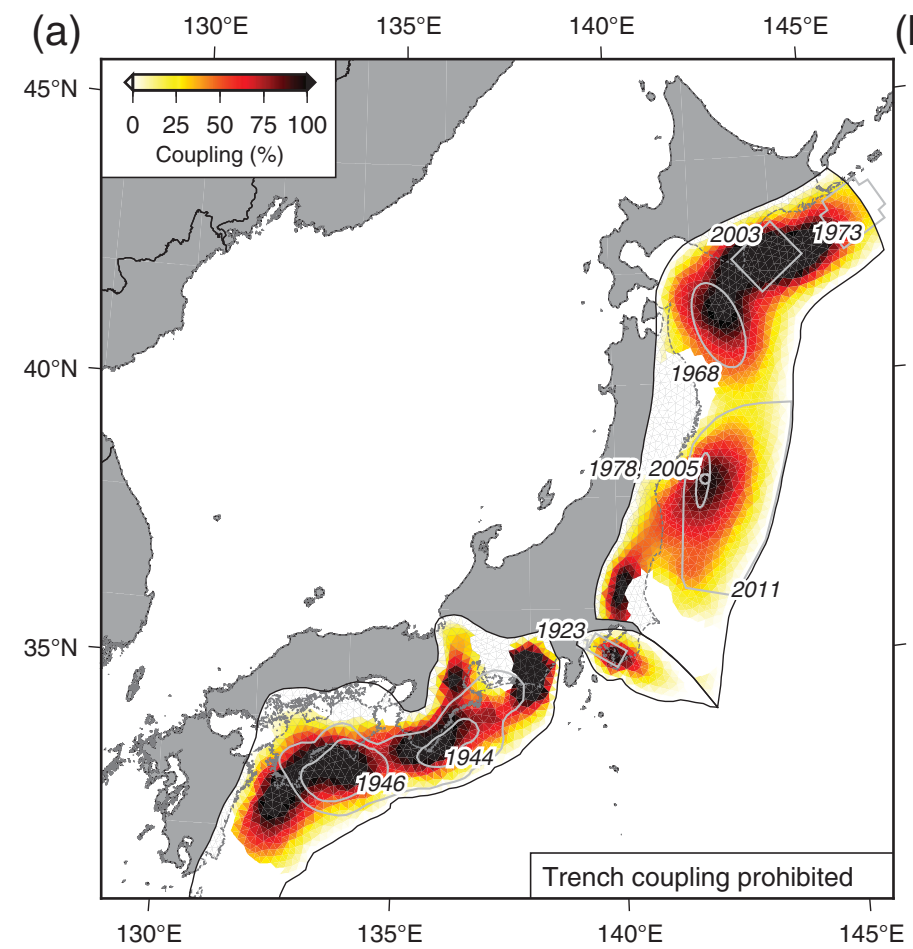

(b)

(b) $\quad 130^{\circ} \mathrm{E} \quad 135^{\circ} \mathrm{E} \quad 140^{\circ} \mathrm{E} \quad 145^{\circ} \mathrm{E}$

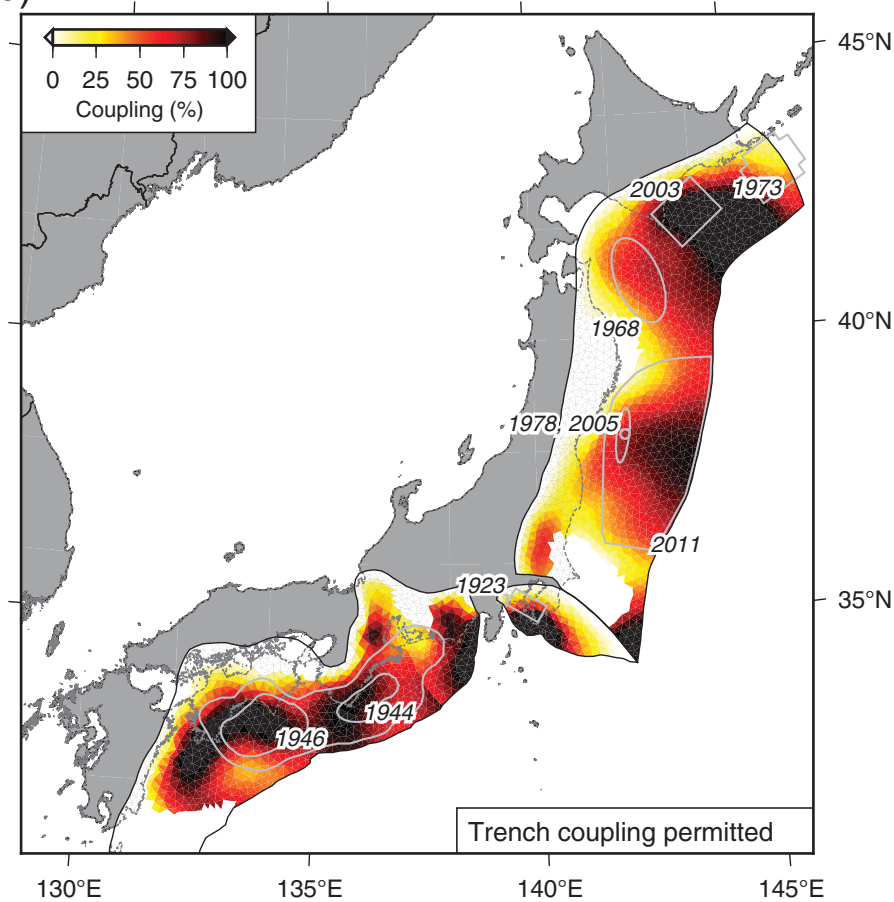

A Figure 2. Heterogeneous geodetically constrained interseismic coupling distributions on the Japan, Nankai, and Sagami subduction zones. Coupling is presented as the fraction of relative plate motion that contributes to elastic strain accumulation. We simultaneously estimate plate motions and slip deficit (backslip) rates on the subduction interfaces, then normalize slip deficit by plate motion to give coupling fraction. The creep at the trench in $(a)$ is consistent with the suggestion that strain cannot accumulate there due to the presence of unconsolidated sediments in the upper plate (Oleskevich et al., 1999), whereas the creep in (b) does not impose this constraint. Darker colors indicate increased coupling. Light gray lines represent modeled rupture extents of historic to recent great earthquakes as follows: $1946 M_{\mathrm{w}} 8.3$ Nankai and $1944 M_{\mathrm{w}} 8.1$ Tonankai, 1 and $3 \mathrm{~m}$ slip contours (showing overall extent of both ruptures and separation of events, respectively; Sagiya and Thatcher, 1999); $1923 M_{\mathrm{w}} \sim 7.9$ Kanto, modeled rupture area (Nyst et al., 2006); $2011 M_{\mathrm{w}} 9.0$ Tohoku-0ki, $4 \mathrm{~m}$ slip contour (Loveless and Meade, 2011); $1978 M_{\mathrm{w}} 7.6$ Miyagi-Oki, aftershock region (Tichelaar and Ruff, 1988); $2005 M_{\mathrm{w}} 7.0$ Miyagi-Oki, epicenter (from USGS); $1968 M_{\mathrm{w}} 8.2$ Tokachi-Oki, aftershock region (Schwartz and Ruff, 1985); $2003 M_{\mathrm{w}} 8.2$ Tokachi-Oki, modeled rupture area (Koketsu et al., 2004); and $1973 M_{\mathrm{w}} 8.0$ Nemuro-Oki, $1 \mathrm{~m}$ slip region (Nishimura, 2009). 

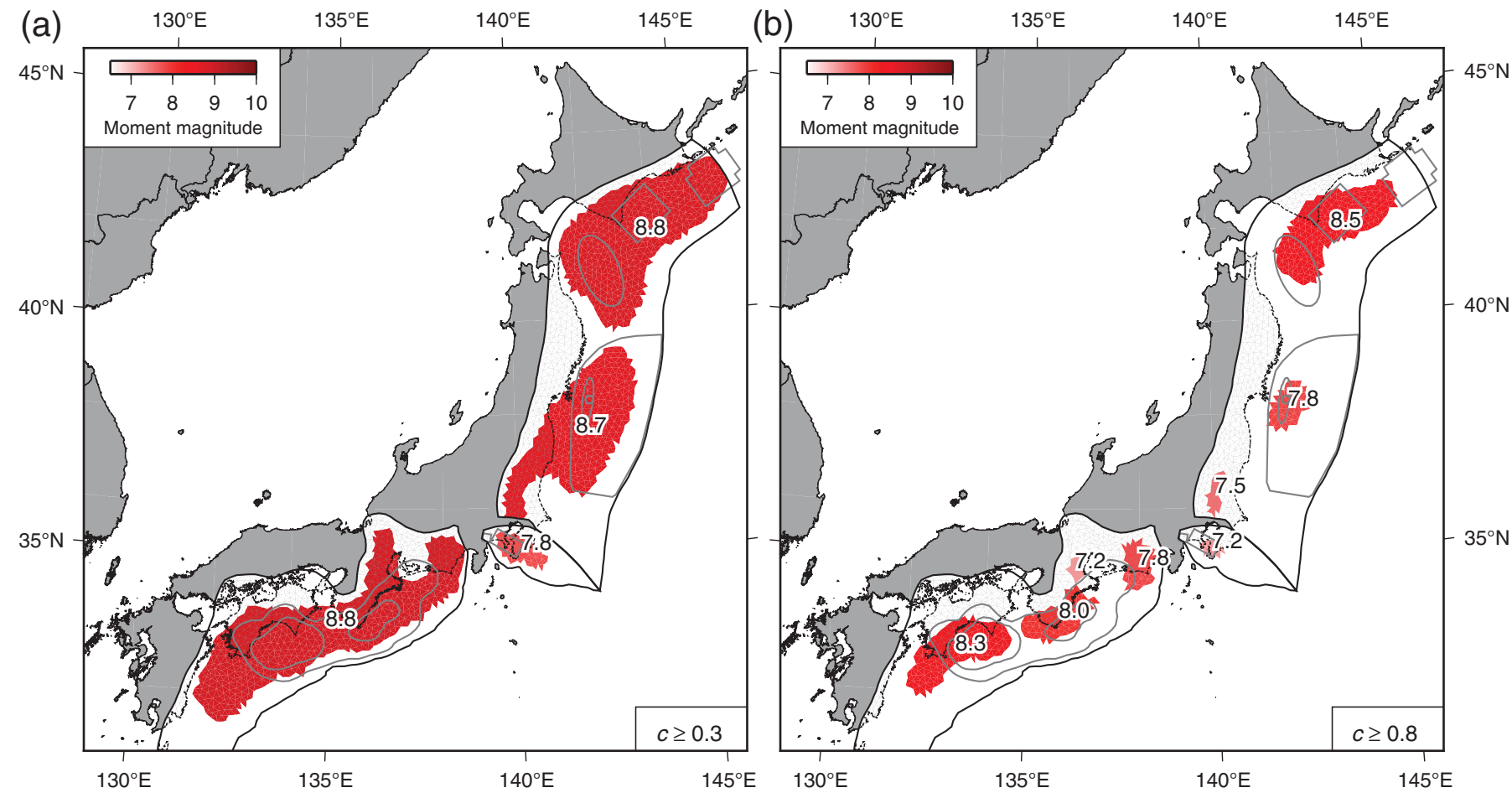

A Figure 3. Potential areas and magnitudes of earthquakes rupturing partially coupled regions of the subduction zones. The areas estimated to be coupled at (a) $30 \%$ and (b) $80 \%$ of the plate convergence rate or greater in the case of enforced creep at the subduction trench (corresponding to Fig. 2a) are represented. Gray contours indicate rupture areas of the earthquakes, as in Figure 2. The potential rupture area offshore of Honshu in (a) is approximately consistent with the extent of the $2011 M_{\mathrm{w}} 9.0$ Tohoku-Oki earthquake. Assuming that the $30 \%$ coupling contour provides similar guidance for estimating future great earthquake ruptures, great earthquakes are possible offshore of Hokkaido, across the entirety of the Nankai subduction zone, and on the western portion of the Sagami subduction zone beneath Tokyo. Aside from the Tohoku-Oki earthquake, the $80 \%$ coupling contour (b) shows better correspondence with twentieth century to recent seismicity nationwide.

prefecture near $40^{\circ} \mathrm{N}$; Fig. 2). Because of the heterogeneous nature of interseismic coupling, potential rupture areas on individual subduction zones may become segmented. For example, with $c \geq 0.8$, the Japan and Nankai subduction zones are segmented into three and four regions, respectively (Fig. 3b). Each of these isolated regions might be considered to rupture separately, with bounding regions of relative lower coupling interpreted as kinematic barriers to earthquake propagation. In other words, the rupture will not propagate through regions with insufficient preearthquake elastic strain accumulation.

Extending this argument, each coupling fraction can be used to define a rupture scenario (Figs. 3, 4; (E) Figs. S1-S10 available in the electronic supplement to this article) across the subduction zones. We estimate rupture scenarios for the coupling fractions $0.1 \leq c \leq 1.0$. At $c \geq 0.3$, the rupture scenario for the Japan subduction zone transitions from a single $M_{\mathrm{w}}$ 9.2-9.3 earthquake to two events centered at $37^{\circ} \mathrm{N}$ $\left(M_{\mathrm{w}} 8.7\right)$ and $42^{\circ} \mathrm{N}\left(M_{\mathrm{w}} 8.8\right)$, respectively (Figs. 3a, 4). The southern of these corresponds most closely to the rupture area of the 2011 Tohoku-Oki earthquake. If this coupling value, the distribution of which best matches the rupture extent of the Tohoku-Oki earthquake, serves as a reference for defining the rupture extent of other large Japan trench earth- quakes, then a similar-size potential earthquake off the southeast coast of Hokkaido would be considered consistent. The $2003 M_{\mathrm{w}} 8.2$ Tokachi earthquake was $\sim 15$ times smaller in moment than this hypothetical off-Hokkaido earthquake and is estimated to have slipped over an area of $1.2 \times 10^{4} \mathrm{~km}^{2}$, with peak slip of $7.1 \mathrm{~m}$ (Koketsu et al., 2004). Despite the massive size of both the Tohoku-Oki and hypothetical off-Hokkaido events, these ruptures would only involve $50 \%$ of the total area of the Japan subduction zone (i.e., regions coupled at $\geq 30 \%$ of the plate rate). Relative plate motion across the rest of the interface may be accommodated by smaller earthquakes and/or aseismic creep.

The rupture scenario corresponding to $c \geq 0.8$ shows greater consistency with all Japan trench earthquakes except the Tohoku-Oki event. In particular, the small patch of strong coupling at $38^{\circ} \mathrm{N}$ latitude is consistent with an $M_{\mathrm{w}} 7.8$ earthquake, which is closer in magnitude to the $2005 M_{\mathrm{w}}$ 7.2 MiyagiOki earthquake (Fig. 3b), as well as the longer-term pattern of $M_{\mathrm{w}} \sim 7$ class earthquakes in this area (Fig. 1; Utsu, 2004). Offshore of Hokkaido, the potential $M_{\mathrm{w}} 8.5$ earthquake exceeds the magnitude of the 2003 Tokachi-Oki earthquake and encompasses the rupture areas of the 2003 earthquake and the 1973 Nemuro-Oki and 1968 Tokachi-Oki earthquakes. This large, whole-Hokkaido rupture is consistent with events inferred 


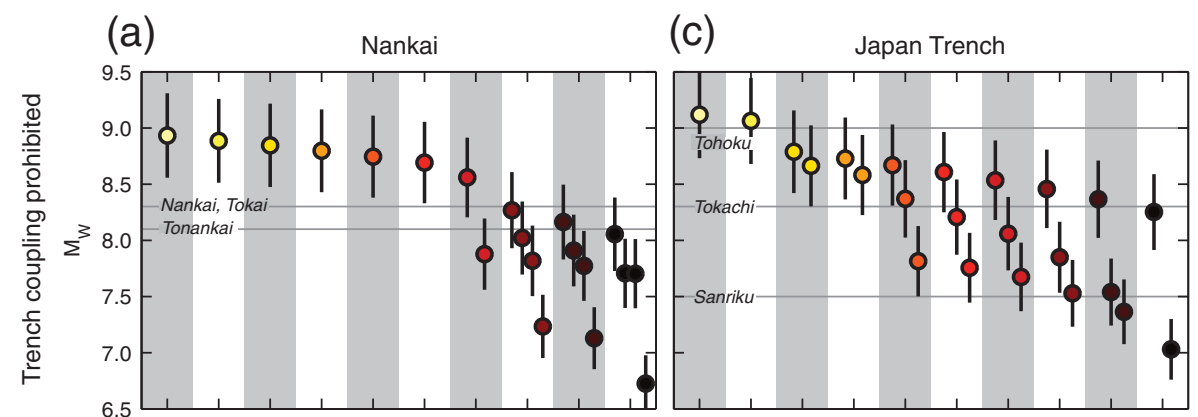

(b)

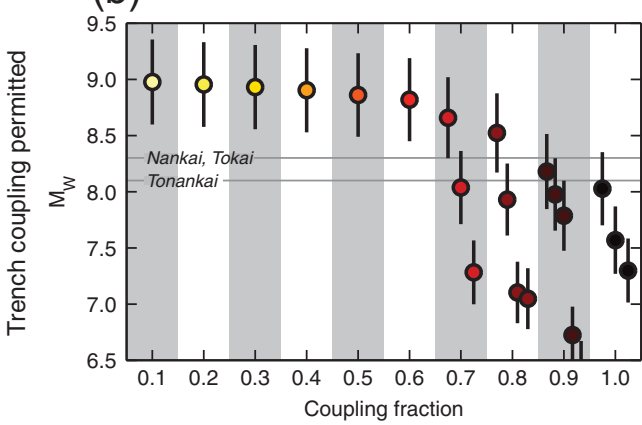

(d)

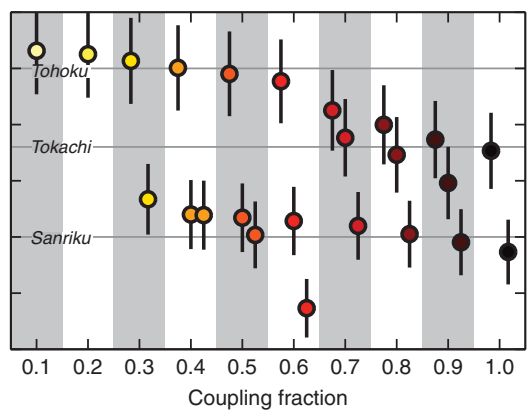

(e)

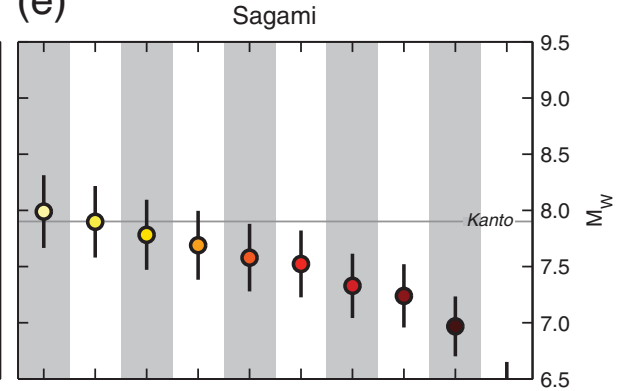

(f)

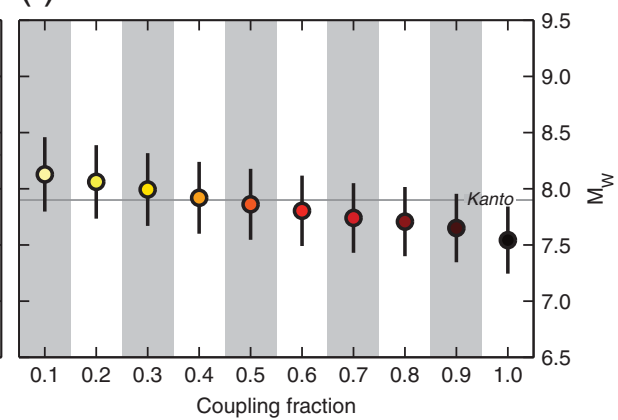

A Figure 4. Potential earthquake magnitudes, assuming that regions of the subduction zones of a given coupling fraction (with bins representing coupling increments of 0.1 ) rupture as discrete events. We determined the total area of the subduction zone estimated at a given coupling level for both the trench creeping and trench coupled scenarios and then used the empirical scaling laws of Wells and Coppersmith (1994) to determine moment magnitude and uncertainties. Multiple points within a bin indicate multiple distinct regions of the given coupling fraction; $x$-axis offset of points is for clarity and is not indicative of a true difference in coupling fraction. Estimated magnitudes of prominent earthquakes on each subduction zone are given as horizontal lines: 1854 Tokai $\left(M_{\mathrm{w}} 8.4\right), 1944$ Nankaido $\left(M_{\mathrm{w}} 8.1\right)$, and 1946 Nankai $\left(M_{\mathrm{w}}\right.$ 8.4) on the Nankai subduction zone; 1994 Sanriku-Oki $\left(M_{\mathrm{w}} 7.4\right)$, 2003 Tokachi-Oki $\left(M_{\mathrm{w}}\right.$ 8.3), and 2011 Tohoku-0ki $\left(M_{\mathrm{w}} 9.0\right)$ on the Japan subduction zone, and 1923 Kanto $\left(M_{\mathrm{w}} 7.9\right)$ on the Sagami subduction zone.

from tsunami deposits that recur roughly every 500 years (Nanayama et al., 2003).

We find a different sensitivity of rupture scenario to coupling coefficient on the Nankai subduction zone. Following the Tohoku-Oki example, a rupture of all $c \geq 0.3$ regions of the Nankai subduction interface could be achieved with a single $M_{\mathrm{w}} 8.9-9.0$ earthquake (Figs. 3a, () S3), similar to that inferred to have occurred in 1707 (Ando, 1975). Between $c \geq$ 0.6 and $c \geq 0.7$, rupture scenarios change from a single large earthquake to two or three smaller earthquakes for the both the trench coupled and the trench free interseismic slip models. For the $c \geq 0.8$ rupture scenario (Figs. 3b, 4), the magnitudes and locations of the two southwestern events are similar to those of the $1944 M_{\mathrm{w}} 8.1$ Nankaido (Tonankai) and $1946 M_{\mathrm{w}} 8.3$ Nankai (Nankaido) earthquakes (e.g., Sagiya and Thatcher, 1999), whereas the northeastern event is broadly consistent with Tokai-type earthquakes, the last of which occurred in 1854 with estimated $M_{\mathrm{w}} 8.4$ (Ishibashi, 1981).

The Sagami subduction zone is smaller in area $\left(2.5 \times 10^{4} \mathrm{~km}^{2}\right)$ than both the Nankai $\left(2.0 \times 10^{5} \mathrm{~km}^{2}\right)$ and Japan $\left(3.0 \times 10^{5} \mathrm{~km}^{2}\right)$ subduction zones but poses a substantial seismic hazard, as evidenced by the $1923 M_{\mathrm{w}} 7.9-8.0$ Kanto earthquake, and risk due to its proximity to metropoli$\tan$ Tokyo. A second contrast with the other two subduction zones is that for all coupling coefficient values, rupture scenar- ios involve only a single earthquake (Fig. 4e,f), ranging in magnitude from $M_{\mathrm{w}} 6.4(c \geq 1.0)$ to $M_{\mathrm{w}} 8.1(c \geq 0.1)$ and always involving slip on the western portion of the subduction zone interface beneath the Boso Peninsula and Tokyo (Fig. 3), which is consistent with estimates of the 1923 rupture (Nyst et al., 2006). The coupling fraction most consistent with the magnitude of the $1923 M_{\mathrm{w}} 7.9$ Kanto earthquake is $c \geq 0.3$.

These rupture scenario estimates are sensitive to the structure and weighting of the smoothing matrix used in the inversion for interseismic slip deficit. Here, we chose a weight for the smoothing that estimates slip deficit exceeding the plate convergence rate on no more than $8 \%$ of elements. In other words, the solution is smoothed as little as possible to avoid unrealistic oscillations in the estimated slip deficit vector. In this sense, the rupture scenarios based on these interseismic coupling distributions may be interpreted as biased toward a greater number of smaller earthquakes rather than a smaller number of large earthquakes that would be inferred from smoother interseismic coupling distributions.

\section{THE INTERPRETATION OF KINEMATIC BARRIERS}

A critical question for this analysis asks "In what sense do kinematic barriers (regions of diminished interseismic strain accumulation) serve to effectively limit the propagation, and 
therefore size, of earthquakes?" A limiting factor in developing an empirical estimate for the coupling fraction that effectively defines the area of future large ruptures is the relatively small number of regions where data have allowed a direct comparison between pre-earthquake interseismic coupling and coseismic slip distributions. The $2012 M_{\mathrm{w}} 7.6$ Nicoya, Costa Rica, earthquake seems to have ruptured a portion of the Middle America trench preseismically coupled at $c>0.6$ (Protti et al., 2014), and the Tohoku-Oki earthquake has been interpreted similarly (Avouac, 2011; Loveless and Meade, 2011), at least in terms of the lateral and down-dip extents of the rupture. More ambiguous agreement between preseismic coupling and coseismic slip distribution characterizes the $2010 M_{\mathrm{w}} 8.8$ Maule, Chile, earthquake (Moreno et al., 2010; Lorito et al., 2011) and the 2007 series of earthquakes offshore Sumatra (Konca et al., 2008). In these latter cases, discrepancies between the coupling and earthquake slip distributions may suggest that long-term geologic traits of the subduction zone fundamentally control great earthquake rupture extents, but that interface behavior is modulated by processes that fluctuate on shorter time scales (i.e., from one seismic cycle to the next, or even within a single seismic cycle), introducing heterogeneity in coupling and/or coseismic slip. Dynamic rupture simulations (Kaneko et al., 2010) based on a rate-state friction fault slip law suggest that the presence of velocity-strengthening materials separating patches of velocity-weakening material may sometimes serve to inhibit the lateral propagation of ruptures on the fault surface, while at other times may allow through-going propagation of a single large earthquake that breaks the distinct patches. However, the dimensions and frictional conditions of a region that are necessary to always limit rupture extents are not yet known.

A further limit to the interpretation of kinematic barriers is the extent to which weakly coupled regions may be ephemeral. Nishimura et al. (2004) document minor changes in the pattern of coupling offshore of northernmost Honshu on an annual basis between 1995 and 2002 but highlight a general persistence in the low-coupling region separating the high-coupling areas offshore of Sendai and Hokkaido. The geodetic era over which these structures have been documented in active subduction zones globally spans little more than twenty years, so there is currently no clear observational evidence regarding the stability of kinematic barriers to rupture over a single or multiple earthquake cycles.

The twentieth century-to-recent seismic behavior offshore of Hokkaido and northern Honshu indicates earthquakes smaller (Fig. 1) than the potential events that are estimated from the coupling analysis (Figs. 3, 4). Prior to the TohokuOki earthquake, events offshore of Sendai $\left(38^{\circ} \mathrm{N}\right)$ were of $M_{\mathrm{w}}$ 7.0-8.1 (Utsu, 2004). The rupture area of the 2003 $M_{\mathrm{w}} 8.2$ Tokachi-Oki earthquake is similar to that estimated for the penultimate event off Hokkaido, the $1952 M_{\mathrm{w}} 8.1$ earthquake (Hirata et al., 2003); and, earthquakes offshore of northernmost Honshu, including the $1994 M_{\mathrm{w}} 7.4$ SanrikuOki event, have been of $M_{\mathrm{w}}$ 7.0-7.9. The $c \geq 0.3$ case rupture scenario (Fig. 3a) shows the potential for an $M_{\mathrm{w}} 8.8$ earthquake breaking a region comprising the Sanriku-Oki,
Tokachi-Oki, and Nemuro-Oki (off eastern Hokkaido) segments together. This is not unprecedented according to tsunami deposits, which suggest such events recurred every 500 years over the past few millennia (Nanayama et al., 2003).

On the Nankai megathrust, the $c \geq 0.8$ scenario (Fig. 3b) is most consistent with the distribution of the latest great earthquakes, wherein the Nankai, Tonankai, and Tokai segments have ruptured in distinct events. On the other hand, the $c \geq 0.3$ scenario (Fig. 3a) shows a potential single, $M_{\mathrm{w}} 8.8-8.9$ earthquake breaking the entire interface, suggesting the possibility of time-variable patterns of great earthquake behavior (e.g., Kodaira et al., 2006). As was demonstrated by the Tohoku-Oki earthquake, past seismic behavior may not be representative of the earthquake potential on any of the subduction interfaces. However, we cannot rule out the possibility of fundamental physical variations between subduction zones that may result in different coupling thresholds in defining kinematic barriers to great earthquake rupture.

The case of the Tohoku-Oki earthquake requires additional consideration as to the relationship between coseismic rupture and interseismic coupling nearest the trench. Here, observations of both a seafloor fold scarp (Kodaira et al., 2012) and upper wedge deformation (Ito et al., 2011) and seafloor geodetic measurements (Kido et al., 2011) suggest the rupture propagated from a hypocentral depth of $30 \mathrm{~km}$ to the trench. To a certain extent, this was considered by some to be unexpected behavior because of the common conceptual model that the near-surface part of a subduction zone is assumed to creep aseismically during the interseismic phase of the seismic cycle (Oleskovich et al., 1999; Saffer and Tobin, 2011). If this were the case, it would seem that the up-dip propagation of the Tohoku-Oki earthquake would be inconsistent with the concept of a significant kinematic barrier, and several rupture dynamics models have been proposed to explain this up-dip propagation (e.g., Kozdon and Dunham, 2013; Noda and Lapusta, 2013). However, interseismic land-based geodetic measurements prior to the Tohoku-Oki earthquake are not sufficient to uniquely resolve the detailed behavior of the subduction zone nearest the trench because of the great distance $(>230 \mathrm{~km})$ to the coastline (Loveless and Meade, 2010, 2011), so direct measurements of interseismic creep are not available. Block models both with and without near-trench creep can explain onshore GPS velocities with a mean residual magnitude of less than $1.9 \mathrm{~mm} / \mathrm{yr}$ (Loveless and Meade, 2011). Although near-trench seafloor geodetic measurements were not available prior to the Tohoku-Oki earthquake, such measurements have been made near the Nazca trench and subduction zone offshore southern Peru (Gagnon et al., 2005). Based on repeat observations of both onshore and seafloor geodetic sites, including one within $25 \mathrm{~km}$ of the trench, these authors estimate that interseismic velocity gradients are consistent with a subduction zone interface that is locked between 2 and $40 \mathrm{~km}$ depth. In other words, the subduction zone interface is interseismically locked almost completely to the trench. If this interpretation is indicative of the behavior of the Japan subduction zones as well as the Nazca subduction zone, then there would be no need to explain the up-dip rupture propagation 
through an uncoupled region; the up-dip region never would have presented a kinematic barrier to rupture and, in fact, should be expected to rupture during a great earthquake.

\section{CONCLUSIONS}

The apparent spatial correspondence of recent coseismic ruptures (Tohoku-Oki in Japan and Nicoya along the Middle America trench) with concentrations of preseismic coupling suggests that these earthquake rupture areas were bounded by regions of relatively low interseismic coupling. More specifically for the Japan trench subduction zone, the $c \geq 0.3$ coupling contour appears to be well correlated with the coseismic rupture extent of the Tohoku-Oki earthquake, whereas regions coupled at $c \geq 0.8$ show spatial correspondence with historical to recent Japanese earthquakes other than Tohoku-Oki. The concept that comparatively low values of interseismic coupling may define kinematic barriers to rupture propagation allows for the identification of discrete potential earthquakes in the future.

If the kinematic barriers that defined the lateral boundaries of the 2011 Tohoku-Oki earthquake serve as a guideline for future events, the prospect for future $M_{\mathrm{w}} 7.8-9.1$ events on four distinct segments of Japan's subduction zones remains undiminished. In general, regions of the Japanese subduction zones coupled at $c \geq 0.8$ may define a more prevalent pattern of earthquake rupture, whereas rare, massive earthquakes such as Tohoku-Oki and past whole-Hokkaido and whole-Nankai events may involve regions preseismically coupled by as little as $30 \%$. Assessing characteristics of the coupling distributions, including their spatiotemporal variations and connections to physical properties, remain important tasks in identifying the future seismic hazard of Japan. $\mathbf{<}$

\section{ACKNOWLEDGMENTS}

Estimates of interseismic coupling were obtained by inverting Global Navigational Satellite System observations from Japan's GNSS Earth Observation Network System, made available by the Geographical Survey Institute. We thank Associate Editor Alan Kafka and two anonymous referees for helpful reviews.

\section{REFERENCES}

Ando, M. (1975). Source mechanisms and tectonic significance of historical earthquakes along Nankai trough, Japan, Tectonophysics 27, 119-140, doi: 10.1016/0040-1951(75)90102-X.

Avouac, J. P. (2011). Earthquakes: The lessons of Tohoku-Oki, Nature 475, 300, doi: 10.1038/nature10265.

Comninou, M. (1973). Angular dislocation in a half space, Ph.D. Dissertation, Northwestern University, Evanston, Illinois, 45 pp.

Evans, E. L., and B. J. Meade (2012). Geodetic imaging of coseismic slip and postseismic afterslip: Sparsity promoting methods applied to the great Tohoku earthquake, Geophys. Res. Lett. 39, doi: 10.1029/2012GL051990.

Furuse, N., and Y. Kono (2003). Slab residual gravity anomaly: Gravity reduction due to subducting plates beneath the Japanese Islands, J. Geodyn. 36, 497-514, doi: 10.1016/S0264-3707(03)00062-0.
Gagnon, K., C. D. Chadwell, and E. Norabuena (2005). Measuring the onset of locking in the Peru-Chile trench with GPS and acoustic measurements, Nature 434, 205-208, doi: 10.1038/nature03412.

Hashimoto, C., A. Noda, T. Sagiya, and M. Matsu'ura (2009). Interplate seismogenic zones along the Kuril-Japan trench inferred from GPS data inversion, Nat. Geosci. 2, 141-144, doi: 10.1038/ngeo421.

Hirata, K., E. Geist, K. Satake, Y. Tanioka, and S. Yamaki (2003). Slip distribution of the 1952 Tokachi-Oki earthquake ( $M$ 8.1) along the Kuril trench deduced from tsunami waveform inversion, J. Geophys. Res. 108, 2196, doi: 10.1029/2002JB001976.

Hirose, F., J. Nakajima, and A. Hasegawa (2008). Three-dimensional seismic velocity structure and configuration of the Philippine Sea slab in southwestern Japan estimated by double-difference tomography, J. Geophys. Res. 113, no. B09315, doi: 10.1029/2007JB005274.

Ishibashi, K. (1981). Specification of a soon-to-occur seismic faulting in the Tokai District, central Japan, based upon seismotectonics, in Earthquake Prediction: An International Review, Maurice Ewing Series 4, D. W. Simpson and P. G. Richards (Editors), American Geophysical Union, Washington, D.C., 297-332, doi: 10.1029/ME004p0297.

Ito, Y., T. Tsuji, Y. Osada, M. Kido, D. Inazu, Y. Hayashi, H. Tsushima, R. Hino, and H. Fujimoto (2011). Frontal wedge deformation near the source region of the 2011 Tohoku-Oki earthquake, Geophys. Res. Lett. 38, L00G05, doi: 10.1029/2011GL048355.

Jeyakumaran, M., J. W. Rudnicki, and L. M. Keer (1992). Modeling slip zones with triangular dislocation elements, Bull. Seismol. Soc. Am. 82, 2153-2169.

Kaneko, Y., J. P. Avouac, and N. Lapusta (2010). Towards inferring earthquake patterns from geodetic observations of interseismic coupling, Nat. Geosci. 3, 363-369, doi: 10.1038/ngeo843.

Kido, M., Y. Osada, H. Fujimoto, R. Hino, and Y. Ito (2011). Trenchnormal variation in observed seafloor displacements associated with the 2011 Tohoku-Oki earthquake, Geophys. Res. Lett. 38, L24303, doi: $10.1029 / 2011 \mathrm{GL} 050057$.

Kodaira, S., T. Hori, A. Ito, S. Miura, G. Fujie, J.-O. Park, T. Baba, H. Sakaguchi, and Y. Kaneda (2006). A cause of rupture segmentation and synchronization in the Nankai trough revealed by seismic imaging and numerical simulation, J. Geophys. Res. 111, no. B09301, doi: 10.1029/2005JB004030.

Kodaira, S., T. No, Y. Nakamura, T. Fujiwara, Y. Kaiho, S. Miura, N. Takahashi, Y. Kaneda, and A. Taira (2012). Coseismic fault rupture at the trench axis during the 2011 Tohoku-Oki earthquake, Nat. Geosci. 5, 646-650, doi: 10.1038/ngeo1547.

Koketsu, K., K. Hikima, S. Miyazaki, and S. Ide (2004). Joint inversion of strong motion and geodetic data for the source process of the 2003 Tokachi-Oki, Hokkaido, earthquake, Earth Planets Space 56, 329-334.

Konca, A. O., J.-P. Avouac, A. Sladen, A. J. Meltzner, K. Sieh, P. Fang, Z. Li, J. Galetzka, J. Genrich, M. Chlieh, D. H. Natawidjaja, Y. Bock, E. J. Fielding, C. Ji, and D. V. Helmberger(2008). Partial rupture of a locked patch of the Sumatra megathrust during the 2007 earthquake sequence, Nature 456, 631-635, doi: 10.1038/nature07572.

Kozdon, J. E., and E. M. Dunham (2013). Rupture to the trench: Dynamic rupture simulations of the 11 March 2011 Tohoku earthquake, Bull. Seismol. Soc. Am. 103, 1275-1289, doi: 10.1785/0120120136.

Lay, T., and H. Kanamori (2011). Japan earthquake, Phys. Today 64, 33-39.

Lorito, S., F. Romano, S. Atzori, X. Tong, A. Avallone, J. McCloskey, E. Boschi, and A. Piatanesi (2011). Limited overlap between the seismic gap and coseismic slip of the great 2010 Chile earthquake, $N a t$. Geosci. 4, 173-177, doi: 10.1038/ngeo1073.

Loveless, J. P., and B. J. Meade (2010). Geodetic imaging of plate motions, slip rates, and partitioning of deformation in Japan, J. Geophys. Res. 115, no. B02410, doi: 10.1029/2008JB006248.

Loveless, J. P., and B. J. Meade (2011). Spatial correlation of interseismic coupling and coseismic rupture extent of the $2011 M_{\mathrm{w}}=9.0$ Tohoku-oki earthquake, Geophys. Res. Lett. 38, doi: 10.1029/ 2011GL048561. 
Meade, B. J. (2007). Algorithms for the calculation of exact displacements, strains, and stresses for triangular dislocation elements in a uniform elastic half space, Comput. Geosci. 33, 1064-1075, doi: 10.1016/j.cageo.2006.12.003.

Moreno, M., M. Rosenau, and O. Oncken (2010). 2010 Maule earthquake slip correlates with pre-seismic locking of Andean subduction zone, Nature 467, 198-202, doi: 10.1038/nature09349.

Nanayama, F., K. Satake, R. Furukawa, K. Shimokawa, B. F. Atwater, K. Shigeno, and S. Yamaki (2003). Unusually large earthquakes inferred from tsunami deposits along the Kuril trench, Nature 424, 660-663, doi: 10.1038/Nature01864.

Nishimura, T. (2009). Slip distribution of the 1973 Nemuro-Oki earthquake estimated from the re-examined geodetic data, Earth Planets Space 61, 1203-1214.

Nishimura, T., T. Hirasawa, S. Miyazaki, T. Sagiya, T. Tada, S. Miura, and K. Tanaka (2004). Temporal change of interplate coupling in northeastern Japan during 1995-2002 estimated from continuous GPS observations, Geophys. J. Int. 157, 901-916, doi: 10.1111/ j.1365-246X.2004.02159.x

Noda, H., and N. Lapusta (2013). Stable creeping fault segments can become destructive as a result of dynamic weakening, Nature 493, 518-521, doi: 10.1038/nature11703.

Nyst, M., T. Nishimura, F. Pollitz, and W. Thatcher (2006). The 1923 Kanto earthquake reevaluated using a newly augmented geodetic data set, J. Geophys. Res. 111, doi: 10.1029/2005JB003628.

Oleskevich, D. A., R. D. Hyndman, and K. Wang (1999). The updip and downdip limits to great subduction earthquakes: Thermal and structural models of Cascadia, south Alaska, SW Japan, and Chile, J. Geophys. Res. 104, 14965-14991, doi: 10.1029/ 1999JB900060.

Protti, M., V. González, A. V. Newman, T. H. Dixon, S. Y. Schwartz, J. S. Marshall, L. Feng, J. I. Walter, R. Malservisi, and S. E. Owen (2014). Nicoya earthquake rupture anticipated by geodetic measurement of the locked plate interface, Nat. Geosci. 7, 117-121, doi: 10.1038/ ngeo2038.

Saffer, D. M., and H. J. Tobin (2011). Hydrogeology and mechanics of subduction zone forearcs: Fluid flow and pore pressure, Annu. Rev. Earth Planet. Sci. 39, 157-186, doi: 10.1146/annurev-earth040610-133408.

Sagiya, T., and W. Thatcher (1999). Coseismic slip resolution along a plate boundary megathrust: The Nankai trough, southwest Japan, J. Geophys. Res. 104, 1111-1129.
Schwartz, S. Y., and L. J. Ruff (1985). The 1968 Tokachi-Oki and the 1969 Kurile Islands earthquakes: Variability in the rupture process, J. Geophys. Res. 90, 8613-8626, doi: 10.1029/Jb090ib10p08613.

Suwa, Y., S. Miura, A. Hasegawa, T. Sato, and K. Tachibana (2006). Interplate coupling beneath NE Japan inferred from three-dimensional displacement field, J. Geophys. Res. 111, no. B04402, doi: 10.1029/ $2004 J B 003203$.

Thomas, A. (1993). POLY3D: A three-dimensional, polygonal element, 9 displacement discontinuity boundary element computer program with applications to fractures, faults, and cavities in the Earth's crust, M.Sc. Thesis, Stanford University, Stanford, California, 69 pp.

Tichelaar, B. W., and L. J. Ruff (1988). Rupture extent of the 1978 Miyagi-Oki, Japan, earthquake and seismic coupling in the northern Honshu subduction zone, Geophys. Res. Lett. 15, 1219-1222, doi: 10.1029/Gl015i011p01219.

Toda, S., R. S. Stein, S. H. Kirby, and S. B. Bozkurt (2008). A slab fragment wedged under Tokyo and its tectonic and seismic implications, Nat. Geosci. 1, 771-776, doi: 10.1038/ngeo318.

Utsu, T. (2004). Catalog of Damaging Earthquakes in the World, http:// iisee.kenken.go.jp/utsu/index_eng.html (last accessed July 2014).

Wells, D. L., and K. J. Coppersmith (1994). New empirical relationships among magnitude, rupture length, rupture width, rupture area, and surface displacement, Bull. Seismol. Soc. Am. 84, 97-1002.

\author{
John P. Loveless \\ Department of Geosciences \\ Smith College \\ 44 College Lane \\ Northampton, Massachusetts 01063 U.S.A. \\ jloveless@smith.edu \\ Brendan J. Meade \\ Department of Earth and Planetary Sciences \\ Harvard University \\ 20 Oxford Street \\ Cambridge, Massachusetts 02138 U.S.A. \\ meade@fas.harvard.edu
}

Published Online 10 December 2014 